under the guidance of Bunsen and Kirchhoff. His first paper, "On the Preparation of the Metals of the Alkalies and Alkaline Earths by Electrolysis," appeared in the Annalen der Chemie und Pharmacie for March 1855 , and was devoted to a description of the preparation and properties of the metals calcium and strontium, then isolated for the first time. Calcium he found to be a metal of the colour and glance of bell metal, exceedingly ductile and malleable; using water as the exciting fluid, he found it to be electropositive to magnesium, and electronegative to sodium and potassium, which at once explained why it could not be obtained from its chloride by the action of sodium or potassium at high temperatures. Next in order is a paper of his in Poggendorf's Annalen for 1857 , communicated by Kirchhoff, in whose laboratory the results were worked out, entitled, "On the Electric Conductivity of Potassium, Sodium, Lithium, Magnesium, Calcium, and Strontium." Following this, appear in Poggendorf's Annalen for I 858 two communications from him "On the Electric Conductivity of Metals," and "On the Thermo-electric Series." On his return to London he worked some time at the Royal College of Chemistry under Hofmann, and published a paper "On the Action of Nitrous Acid on Aniline." Hunt had described phenol, free nitrogen and water as the products of this reaction, but he found that an intermediate reaction took place, by which ammonia was formed; extending his experiments to ethyl and diethylaniline, he obtained ethylamine and diethylamine. It was this reaction which first led him to the study of narcotine, which afterwards in his hands yielded such splendid results. After working diligently several years in a laboratory which he fitted up for him. self in Torrington Square, he was appointed Professor of Chemistry to St. Mary's Hospital in 1862 . It was about this period that his most important researches were carried out in conjunction with Dr. Vogt, Von Bose, Holzmann, \&c., and published in a series of papers in the Philosophical Transactions of the Royal Society, to which he was admitted a Fellow in $186 \mathrm{r}$. Some of the most important of these papers are those "On the Influence of Temperature on the Electric Conducting Power of Metals." It was this research which proved the important fact, that the conducting power of the pure metals decreased to the same extent between $0^{\circ}$ and $100^{\circ} \mathrm{C}$.; two remarkable exceptions, however, to this law, Iron and Thallium were the subject of a later paper; "On the Specific Gravity of Metals and Alloys;" "On the Chemical Nature of Alloys," in which he showed that nearly all the two-metal alloys may be considered as solidified solutions of the one metal in the other. Also a long series of determinations of the influence of temperature on the conducting power of alloys. He also made a most careful redetermination of the expansion of water and mercury, and found that Kopp's coefficients were slightly too low. He was a very active member of the committee appointed by the British Association "On the Standards of Electrical Resistance," and it was one of the alloys discovered by him which was finally adopted for the reproduction of the now well known B A unit of electrical resistance. His later chemical work is embodied in a series of papers in the Philosophical Transations-" On the Chemical Constitution of Narcotine"-published partly in conjunction with Prof. Foster, and partly with Dr. Wright. In these he shows that one, two, and three atoms of methyl can be successively removed from narcotine, and also describes a large number of interesting derivatives of the same. In 1869 he was appointed Professor of Chemistry in St. Bartholomew's Hospital, and in the same year received the Royal Society's Gold Medal for his published researches on the metals and the opium alkaloids. One of the most important results of his last investigation is the discovery of the relation between morphia and codeia, the latter simply containing one of methyl more than the former; alhough, however, he succeeded in obtaining apomorphia from codeia, he was never able to reconvert apomorphia into morphia, and thus form morphia direct from codeia. At the time of his death he was occupied with the experiments on the chemical nature of pure castiron, of the Committee appointed to inquire into which he was a member, and also with experiments with a view to determine whether the specific heat of platinum was constant at high temperatures, and if so, to employ it in the construction of a standard pyrometer. He was also prosecuting his researches on the opium bases, and had already arrived at interesting results, which we believe will shortly be published. All the beforementioned researches display an enormous amount of manipulative skill, and there is little doubt that his success was mainly due to the wonderful acuteness of his powers of observation, and also to his great perseverance ; but it is indeed surprising that, labouring under the physical disadvantages he did, he should have been able to attain such ends.

At a time when England can least afford it, she has lost one who had not only done a vast amount of valuable work, but who, there was every prospect, would do as much more in the future.

\section{BRITISH EDIBLE FUNGI}

MUSHROOMS and their congeners seem never $\mathrm{W}$ have been in good repute since Agrippina employed one of the tribe to poison her husband, and Nero with villanous pleasantry called it the "food of the gods." With proverbial tenacity the bad name thus incurred has clung to the whole family of agarics, and what within certain limits might be called a wholesome dread has become a deep-rooted and irrational prejudice, excluding from popular use a really valuable class of vegetable esculents. We cannot altogether go along with those enthusiastic mycophagists who recognise a substitute for meat in every edible fungus, and dilate on the ozmazome and other nutritious properties of the tribe; but we readily acknowledge that their merits as secondary sources of food-supply have hitherto been unduly neglected. The great difficulty always felt in advocating the claims of the class to more extensive use has arisen from the want of some definite rules, some formula at once simple in expression and universal in application, by which to distinguish the noxious from the innocent members. Pliny, in his Natural History, goes so far as to say that the first place amongst those things which are eaten with peril must be assigned to agarics, and he expresses his surprise at the pleasure which men take "in so doubtful and dangerous a meat." But his observations show that fungi of all sorts, including even such growths as the Fistulina hepatica, were known to his countrymen and eaten by them without scruple. Indeed, in one particular the wisdom of the ancient Romans seems to have been superior to that of their descendants, for, while Horace lays down the rule-

\section{Pratensibus optima fung}

the modern $A$ diles of the Roman market condemn to instant destruction every specimen of the meadow mushroom ( $A$. campestris) which comes within their reach. Although, however, it is not always easy to distinguish the wholesome from the unwholesome fungus, and the organs of sight and smell require some training before they can be wholly trusted in the matter, yet the dangers have been greatly exaggerated, and, as a matter of fact, hogweed is more often mistaken for parsnip and aconite for horseradish than are Boletus sátanas and Amanita verna for their innocent brethren. No better opportunity for engaging in the study of this branch of natural history could be found than that which the present season affords; and if the treatises of Mr. Berkeley, Dr. Badham, or Mr. Worthington Smith be not at hand, the following notes on 
the chief edible fungi which are now to be met with may prove acceptable to some of our readers.*

With the ordinary meadow mushroon (A. compestris) and its near relative the horse mushroon ( $A$. arvensis) every one is familiar, and both of them have occurred in profusion this autumn. Against the latter an unfounded prejudice prevails in some districts, but its larger size and coarser texture require only a little extra cooking to develop the flavour and correct indigestibility. In spite of all that has been said to the contrary, we maintain that these agarics are entitled to the first place, and for the second much rivalry exists between the orange-milk mushroom (Lactarius deliciosus) and the Parasol Agaric (Agaricus procerus). Both are readily distinguishable, and may be eaten with equal impunity. The former is chiefly found in plantations of Scotch fir and larch, is of an orange-brown colour, and firm flesh, and yields, when bruised, an exudation of orange-red milk, which turns green after a few minutes' exposure. The latter is common in pastures, and may be recognised by its tall habit, the stalk gradually enlarging at the base, the umbo of a brownish colour with spots or patches, and the gills white and unconnected with the stem. The plum

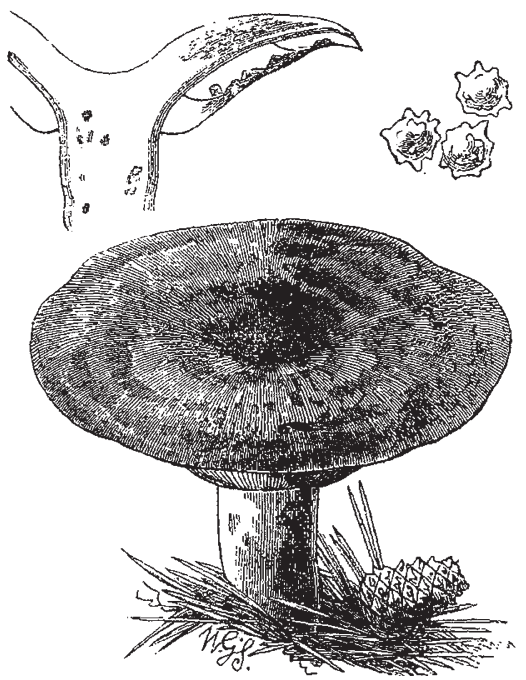

EIG. I. - Lactarius deliziosus (Orange-milk Mushroom). Under fir-trees, in autum!n ; colour, brown-orange ; milk at first orange, then green; diameter, 3 to 10 inches.

mushroom ( $A$. prunulus) is for the autumn months what the St. George's mushroom (A.gambosus) is for the spring - a large fieshy fungus, delicate in flavour, though not so choice as the Orcella, for which it is often mistaken. It is to be found in shady places pretty generally throughout England, and is conspicuous from its whiteness. The gills are close together and of a pale rosy hue, and the smell of the plant has been compared to that of fresh ineal.

We must mention two other fungi, common enough and easily recognised, but of their culinary virtues we do not entertain a very high opinion. These are the puff-ball, and the maned agaric (Coprinus comatus). The former needs no description, and perhaps others may be more fortunate than we have been in detecting the latent flavour of omelette which it is said to possess. The latter is called by Dr. Bull the "agaric of civilisation." We have met with it in farmyards, on lawns, on railway-cuttings, and, in fact, in nearly every waste place. It looks like an attenuated cocoon, snow-white at first, but gradually changing in colour and splitting upwards in a dozen places. The gills, white at first, become pink and then * At the conclusion of "Mushroom Culture, its Extension and Improvement " (London: Warne, 1870), Mr. W. Robinson gives some useful inings of the Wcolbope Field Clut. black ; the last stage, which is very quickly reached, presaging the immediate dissolution of the plant, which gradually deliquesces into an inky-black fluid.

It would be easy to amplify this list, but we desire to avoid all risk of confusing the tyro's mind with too many details, and have purposely confined our remarks to those fungi which belong to the autumn season.

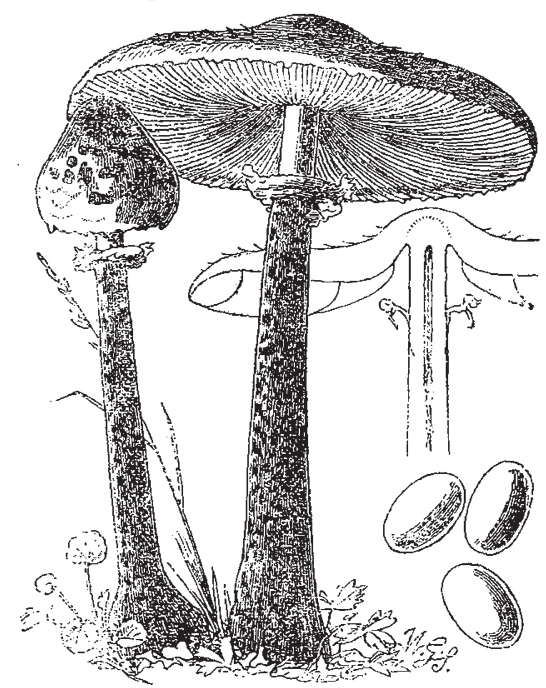

FIG. 2.-Agaricus procerus (Scaly Mushroom). Pastures, \&c., in autumn colour, pale brownish buff; diameter, 5 to 12 inches.

One caution must be added. All agarics are more wholesome fresh than stale, and with some the neglect of this rule may lead to unpleasant consequences. It is rigidly enforced in the Roman market, where all specimens which are "muffi, guasti," or "verminosi" are seized" and thrown into the Tiber, and it should be distinctly understood in every English kitchen into which even the common mushroom is allowed to enter. The fungus which to-day successfully simulates a sweetbread, may tomorrow simulate with equal success a handful of snuff.

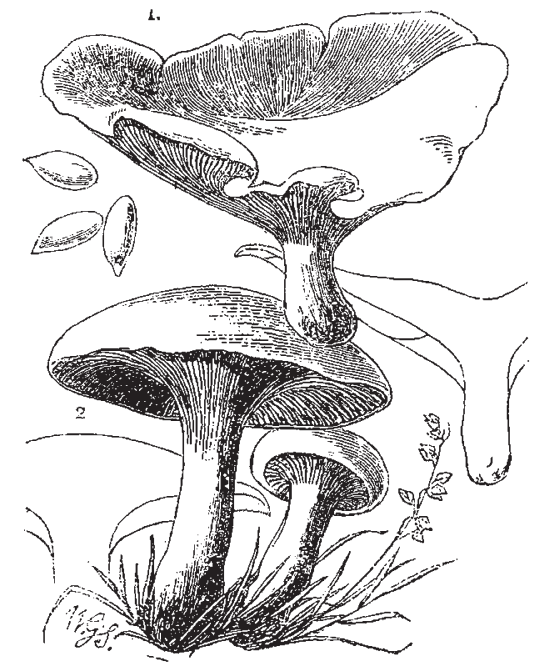

FIG. 3.-(x) Agaricus orcella and (2) Agaricus prumulus (Plum Mushroom Woody places, in autumn; colour, snow white, with pale rose gills; diameter, 2 to 4 inches.

Our illustrations are taken from Mr. W. Robinson's admirable little manual, to which we have already alluded, and are from the facile pencil of Mr. Worthington Smith. Here will be found also instructions for cooking all the most conmon edible species. 